\title{
Determination of Indications for Surgical Treatment with a Combination of Stenosis and Tortuosity of the Internal Carotid Artery in Acute Ischemic Stroke
}

\author{
Stanislav Ordynets ${ }^{1 *}$ and Ivan Dudanov ${ }^{2}$ \\ ${ }^{1}$ PhD of Medicine, City Mariinsky Hospital, St. Petersburg, Russian Federation \\ ${ }^{2}$ Doctor of Medicine, Professor, Corresponding member of the Russian Academy of Sciences, Russian Federation \\ *Corresponding author: Stanislav Ordynets, PhD of Medicine, City Mariinsky Hospital, St. Petersburg, Russian Federation
}

\begin{tabular}{l}
\hline ARTICLE INFO \\
ABSTRACT \\
\hline
\end{tabular}

Received: 慧 August 18, 2020

Published: 幽 August 28, 2020
Keywords: Acute Stroke; Internal Carotid Artery; Carotid Stenosis; Magnetic Resonance Angiography; Carotid Endarterectomy; A Surgical Treatment; Blood Flow Velocity

Citation: Stanislav Ordynets, Ivan Dudanov. Determination of Indications for Surgical Treatment with a Combination of Stenosis and Tortuosity of the Internal Carotid Artery in Acute Ischemic Stroke. Biomed J Sci \& Tech Res 29(5)-2020. BJSTR. MS.ID.004867.

\section{Short Communication}

Ischemic stroke (IS) is one of the main reasons of morbidity, mortality and disablement all over the world. The study of the acute phase of disease has fundamental meaning of medical assistance development for the stroke sufferers [1]. The palindromia risk for stroke sufferers amounts from 5 to 20 percent within the first 30 days (the risk factors are severe stenosis, kinking, unstable plaque, floating thrombus) [2].

\section{Study Purpose}

To prove the surgical treatment effectiveness of the combination of stenosis and carotid artery pathological deformation in comprehensive rehabilitation of patients in acute phase of ischemic stroke.

\section{Materials and Techniques}

From 281 patients operated for acute IS, 112 (39,9\%) had associated atherosclerotic stenoses with kinking of the internal carotid artery. In case of combined pathology, the risk of recurrent stroke is rising steeply. In spite of modern level of carotid surgery, the risk of conversion from the ischemic lesion into the hemorrhagic infarction focus remains as the main argument to delay operation.

There were 3 groups defined:

a) I Group - Patients, who had IS or transient ischemic attack and who were operated within 2 weeks from the beginning of acute cerebrovascular accident - 47 (42\%) patients, 31 (66\%) male, 16 (34\%) female were among them.

b) II Group - Patients, who had IS or transient ischemic attack and who were operated from 2 to 4 weeks from the beginning of acute cerebrovascular accident - $10(8,9 \%)$ patients, $8(80 \%)$ male, 2 (20\%) female were among them.

c) III Group - Patients, who had IS and who were operated later than one month from the beginning of acute cerebrovascular accident - 55 (49,1\%) patients, 34 (61,8\%) male, $21(38,2 \%)$ female were among them. 
For the operative treatment preference was given to the method of the resection of internal carotid artery with its redressement and reimplantation upon specific indications. Contraindications to this surgery were: intimal proliferation in the area of maximum bending - "septal kinking" and expressed degenerative changes in the area of this bending, which impede to spread vessel adequately during redressement attempt or microaneurysmal changes in the arterial wall. In case of kinking with septal stenosis the resection of the crimp zone with anastomosis end to end was performed.

\section{Research Results}

For surgery safety evaluation perioperative complications were taken into account, first of all from the position of the evaluation of the risk of hemorrhagic transformation of ischemic stroke after restoration of blood flow through the early carotid reconstruction, made in different periods of acuity. Results evaluation was made in condition of such characteristically identity of the groups as sex, age, co-morbidity, nature of kinking, degree of stenosis, severity of neurological deficit, etc. The positive dynamics of neurological symptoms was observed in group I for $46(97,9 \%)$ patients, in group II for $8(80 \%)$ patients, in group III for $43(76,2 \%)$ patients. It should be noted that full recovery had almost every third patient in group I and II. The neurological complications had 1 patient (group III) and lethality had 1 patient (group III). Hemorrhagic transformation of brain infarction focus after carotid artery reconstruction wasn't observed in our research.

To determine the operation time, the severity of neurological disease and co-morbidity should be taken into account. For the patients with severe neurological deficit and for patients who had IS, early reconstruction of carotid artery increase the efficiency of the functional recovery, broken during stroke due to improved cerebral perfusion and activation of neuroplasticity in the early stages of acute cerebral ischemia $(p<0,05)$. The beneficial effect after reconstructive surgery on carotid artery of patients with moderate or severe neurological deficit is more pronounced than in the absence of neurologic symptoms or when the minor severity. Taking into account international recommendations, in the acute period of IS the reconstruction of carotid artery with the value of the NIHSS scale more than 12 wasn't performed. It was determined that the most effective terms of reconstructive operations on carotid arteries are the first 2 weeks from the beginning of the development of the brain catastrophe.

\section{Conclusion}

Considering the analysis of frequency of postoperative complications, we determined that the patients with combined stenosis and kinking of the internal carotid artery who were operated without significant delay, have higher probability of the complete regression of neurological symptoms and consequently, disability reduction and restoration of the original employability in comparison with patients who were operated it terms of 4 or more weeks after the first symptoms appearance $[3,4]$.

\section{References}

1. Adams RJ, Albers G, Alberts MJ, Benavente O, Furie K, et al. (2008) Update to the AHA/ASA recommendations for the prevention of stroke in patients with stroke and transient ischemic attack. Stroke 39(5): 1647-1652.

2. Bokeria LA, Gudkova LA (2013) Cardiovascular surgery-2012: diseases and congenital anomalies of the circulatory system. Moscow: Bakulev national research center of the Russian Academy of medical Sciences, pp. 210.

3. Ordynets SV, IP Duoanov (2016) Determinareaindicatiilor Pentru Tratamentul Chirurgicalin Cazul Stenozelor Associate $\mathrm{Cu}$ Kinking $\mathrm{Al}$ Artereicarotide Interne La Pacientii $\mathrm{Cu}$ Arac Ischemic Cerebral Acut. The $2^{\text {nd }}$ congress of romanian society for vascular surgery abstracts volume ISSN: 2537-3498, 2016, 87.

4. Ordynets SV, IP Dudanov (2016) Determination of indications for surgical treatment with a combination of stenosis and tortuosity of the internal carotid artery in acute ischemic stroke. City Mariinsky Hospital, St. Petersburg. The $2^{\text {nd }}$ congress of romanian society for vascular surgery volume de rezumate issn: 2537-3498, 89
ISSN: 2574-1241

DOI: $10.26717 /$ BJSTR.2020.29.004867

Stanislav Ordynets. Biomed J Sci \& Tech Res

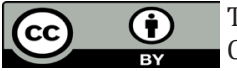

This work is licensed under Creative Commons Attribution 4.0 License

Submission Link: https://biomedres.us/submit-manuscript.php

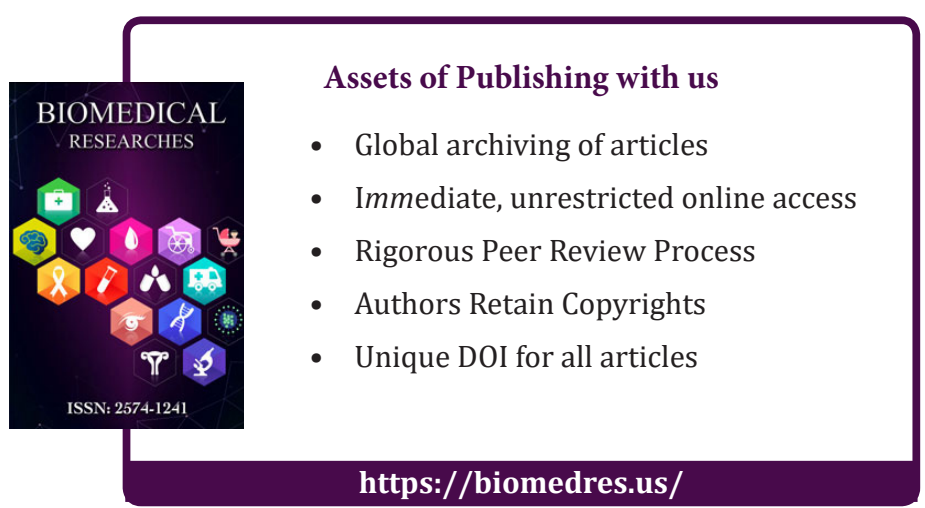

